\title{
O CRUZAMENTO ENTRE GÉNERO E NACIONALIDADE E A PERSPETIVA DA REGULAÇÃO DE CONTEÚDOS MEDIÁTICOS
}

\section{Resumo}

A Entidade Reguladora para a Comunicação Social (ERC) tem como missão regular e supervisionar os media em Portugal. A ação do regulador no combate à discriminação de género nos conteúdos mediáticos enquadra-se nos seus Estatutos, que vinculam esta intervenção à proteção de direitos, liberdades e garantias constitucionalmente protegidos. O exercício do regulador na eliminação dos estereótipos e combate à discriminação de género através dos media é coadjuvado pelos normativos setoriais e diplomas nacionais e internacionais. $\mathrm{O}$ presente artigo reflete sobre a ação da ERC no combate à discriminação e à estereotipização baseada no género nos conteúdos mediáticos e sobre como tem intervindo em situações em que esta forma de discriminação se associa a outras assentes, designadamente, na nacionalidade.

Palavras-chave: Regulação dos media, Igualdade, Género, Nacionalidade, Não-Discriminação.

\begin{abstract}
The intersection between gender and nationality and the perspective of the regulation of media contents

The Regulatory Authority for the Media (ERC) is responsible for media regulation in Portugal. The role of the regulator in the fight against gender stereotyping and discrimination through the media is framed by its Statutes, which direct its intervention in the protection of constitutionally protected rights, freedoms and guarantees. The task of the Regulatory Authority for the Media in eliminating stereotypes and combating gender discrimination through the media is supported by existing national and international legal frameworks. The present paper discusses the intersection of various forms of gender discrimination and stereotyping in media contents, namely in relation with the country of origin.
\end{abstract}

Keywords: Media regulation, Equality, Gender, Nationality, Non-Discrimination

\section{Resumen}

La relación entre género y nacionalidad, así como la perspectiva de la regulación de los contenidos mediáticos

La Entidad Reguladora para la Comunicación Social (ERC) tiene como misión regular y supervisar las entidades dedicadas a la comunicación social en Portugal. La ERC, en el

SOCIUS/ISEG e Entidade Reguladora para a Comunicação Social, Portugal.

Endereço postal: ERC, Av. 24 de Julho, 58, 1200-869 Lisboa, Portugal.

Endereço eletrónico: afigueiredo@erc.pt

Universidade Lusófona de Humanidades e Tecnologias e Entidade Reguladora para a Comunicação Social, Lisboa, Portugal. Centro Interdisciplinar de Estudos de Género, Instituto Superior de Ciências Sociais e Políticas, Portugal.

Endereço eletrónico: carla.martins@erc.pt 
combate de la discriminación de género en los medios de comunicación social, actúa para proteger los derechos, las libertades y las garantías consagrados en la Constitución, como también vela por el cumplimiento de los reglamentos sectoriales y los acuerdos nacionales e internacionales que evocan la eliminación de los estereotipos y que luchan contra la discriminación de género en los contenidos mediáticos. El presente artículo tiene como objetivo discutir las diversas formas de discriminación y los estereotipos de género en los contenidos mediáticos, en particular, aquellos relacionados con el país de origen.

Palabras-clave: Regulación de los medios, Equidad, Género, Nacionalidad, No discriminación

\section{Enquadramento: a Entidade Reguladora para a Comunicação Social e as questões da igualdade e da não discriminação}

A Entidade Reguladora para a Comunicação Social (ERC) é o regulador da comunicação social em Portugal, ${ }^{1}$ criado em 2005 em cumprimento de uma disposição constitucional. ${ }^{2}$ A ERC regula e supervisiona as entidades que desenvolvem atividades de comunicação social sob jurisdição do Estado português, abarcando, entre outros, as publicações periódicas, os operadores de rádio e de televisão, os serviços de programas distribuídos exclusivamente pela Internet e as agências noticiosas.

Juridicamente, define-se como pessoa coletiva de direito público, dotada de autonomia administrativa e financeira e de património próprio, com natureza de entidade administrativa independente. Os seus Estatutos determinam que a ERC se rege pelo princípio da especialidade, o que significa que a sua capacidade jurídica abrange exclusivamente os direitos e obrigações necessários à prossecução das respetivas atribuições. Por conseguinte, o exercício dos poderes de regulação e de supervisão da ERC está balizado pela Constituição, pela lei e pelos próprios Estatutos, não podendo o regulador dos media atuar fora deste enquadramento.

A intervenção do regulador no âmbito do combate à discriminação de género enquadra-se nos seus Estatutos, que vinculam a atuação regulatória, em primeira instância, à proteção de direitos, liberdades e garantias constitucionalmente protegidos. Concretamente, aquele diploma estipula que constituem objetivos da regu-

1 A ERC rege-se pelas normas previstas nos seus Estatutos, aprovados pela Lei n. ${ }^{\circ}$ 53/2005, de 8 de Novembro, tendo iniciado funções após a tomada de posse do Conselho Regulador, órgão responsável por definir e implementar a ação de regulação dos órgãos de comunicação social, a 17 de Fevereiro de 2006.

2 O artigo 39. ${ }^{\circ}$ da Constituição da República Portuguesa prevê a existência de uma entidade administrativa independente para regular a comunicação social. Entre as suas competências, cabe-lhe assegurar o direito à informação e a liberdade de imprensa; a não concentração da titularidade dos meios de comunicação social; a independência perante o poder político e o poder económico; o respeito pelos direitos, liberdades e garantias pessoais; a possibilidade de expressão e confronto das diversas correntes de opinião. 
lação «promover e assegurar o pluralismo cultural» e «assegurar a proteção dos direitos de personalidade individuais». ${ }^{3}$ É ainda sua atribuição a garantia do «respeito pelos direitos, liberdades e garantias». ${ }^{4} \mathrm{~A}$ ação do regulador dos media está umbilicalmente ligada à salvaguarda da cidadania e dos direitos dos cidadãos, princípios fundadores da sociedade democrática baseada na dignidade humana e nos direitos fundamentais.

Segundo Jónatas Machado e Iolanda Brito $(2013,160)$, «A regulação da comunicação social é indissociável dos valores e princípios constitucionais fundamentais da liberdade individual, da universalidade, da igualdade, da justiça, do Estado de direito e da democracia política, económica, social e cultural».

Evoca-se o princípio constitucional da igualdade de direitos, ${ }^{5}$ que impõe que se reconheça a todos os cidadãos a mesma dignidade social e a igualdade perante a lei, independentemente da sua ascendência, sexo, raça, língua, território de origem, religião, convicções políticas ou ideológicas, instrução, situação económica, condição social ou orientação sexual. Enquanto princípio estruturante de um Estado de direito democrático e social, compreende três dimensões essenciais: a da igualdade de todos os cidadãos, a da proibição de discriminação e a da exigência de eliminação das desigualdades fácticas que constituam obstáculo a uma igualdade real ou material.

A proibição e condenação das práticas que discriminam em função da ascendência, sexo, raça, língua, território de origem, religião, convicções políticas ou ideológicas, instrução, situação económica, condição social ou orientação sexual, quando da responsabilidade dos órgãos de comunicação social, encontram-se devidamente salvaguardadas na legislação setorial.

A Lei da Televisão e dos Serviços Audiovisuais a Pedido e a Lei da Rádio determinam que a respetiva programação destes meios «deve respeitar a dignidade da pessoa humana e os direitos, liberdades e garantias fundamentais», sendo interdito o incitamento «ao ódio racial, religioso, político ou gerado pela cor, origem étnica ou nacional, pelo sexo, pela orientação sexual ou pela deficiência». ${ }^{6}$

A Lei de Imprensa define como únicos limites à liberdade de imprensa «os que decorrem da Constituição e da lei, de forma a salvaguardar o rigor e a objetividade da informação, a garantir os direitos ao bom nome, à reserva da intimidade da vida privada, à imagem e à palavra dos cidadãos e a defender o interesse público e a ordem democrática». ${ }^{7}$

Já o Estatuto do Jornalista determina como dever fundamental destes profissionais «não tratar discriminatoriamente as pessoas, designadamente em função

\footnotetext{
Estatutos da ERC, artigo 7. ${ }^{\circ}$, alíneas a) e f).

Estatutos da ERC, artigo 8. ${ }^{\circ}$, alínea d).

Constituição da República Portuguesa, artigo 13. ( (Princípio da Igualdade»), números 1 e 2.

Lei n. ${ }^{\circ}$ 27/2007, de 30 de Julho, artigo 27. ${ }^{\circ}$, números 1 e 2; Lei n. ${ }^{\circ}$ 54/2010, de 24 de Dezembro, artigo $30 .^{\circ}$, números 1 e 2.

Lei n. ${ }^{\circ}$ 2/99, de 13 de Janeiro, artigo $3 .^{\circ}$
} 
da cor, raça, religião, nacionalidade ou sexo», ${ }^{8}$ o mesmo estatuindo o ponto 8 do Código Deontológico do Jornalista. ${ }^{9}$

Acessoriamente, convocam-se documentos de referência nacionais e internacionais, destacando-se, antes de mais, os planos nacionais para a Igualdade de Género, Cidadania e Não Discriminação. O V Plano Nacional para a Igualdade de Género, Cidadania e Não Discriminação ${ }^{10}$ refere a preocupação com a transmissão de mensagens e imagens estereotipadas do ponto de vista das relações e dos papéis de género, nos conteúdos relacionados com o entretenimento ou publicidade, mas também nos conteúdos informativos. Naquele documento, entre os objetivos estratégicos contidos na área da comunicação social, propõe-se a capacitação dos/as profissionais de comunicação para a introdução da dimensão de género nos conteúdos por si produzidos e/ ou editados; a criação de mecanismos de sinalização de conteúdos jornalísticos e publicitários sexistas e estereotipados do ponto de vista do género; e a sensibilização do público para as questões da igualdade de género e não-discriminação.

Entre os diplomas internacionais, a Declaração e Plataforma de Ação de

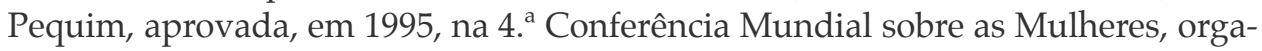
nizada pela ONU, apela ao envolvimento dos governos, da comunidade internacional e da sociedade civil, incluindo as organizações não-governamentais e o setor privado para desenvolver ações estratégicas no combate aos estereótipos sobre as mulheres e à desigualdade do acesso e participação destas a todos os sistemas de comunicação, em particular aos media. Neste sentido, no que diz respeito aos meios de comunicação social, consideram-se como áreas de intervenção prioritárias aumentar a participação das mulheres nos processos de tomada de decisão nos e através dos media e nas novas tecnologias de comunicação e promover um retrato equilibrado e não estereotipado das mulheres nos media (cfr. Declaração e Plataforma de Ação de Pequim).

A Estratégia para a Igualdade de Género 2014-2017, do Conselho da Europa, integra as recomendações contidas na Declaração de Pequim, desenhando como objetivo estratégico o combate aos estereótipos de género e sexismo através da promoção de uma imagem positiva e não estereotipada de mulheres e homens nos media e de uma participação equilibrada de ambos nas posições de liderança das organizações mediáticas.

Em 2013, o comité de ministros do Conselho da Europa emitiu uma recomendação sobre igualdade de género e media, na qual afirma que a igualdade de

$8 \quad$ Lei n. ${ }^{\circ} 1 / 99$, de 13 de janeiro, artigo $14 .^{\circ}$, alínea e).

9 «O jornalista deve rejeitar o tratamento discriminatório das pessoas em função da cor, raça, credos, nacionalidade ou sexo», Código Deontológico do Jornalista, aprovado em 1993, em Assembleia Geral do Sindicato dos Jornalistas (disponível em: http://www.lusa.pt/lusamaterial/PDFs/ CodigoDeontologicoJornalista.pdf).

10 O V Plano Nacional para a Igualdade, Cidadania e Género (2014-2017) foi aprovado por Resolu-

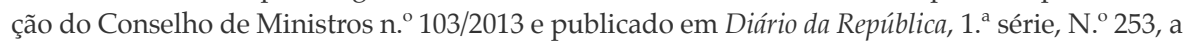
31 de dezembro de 2013. 
género significa igual visibilidade, capacitação, responsabilidade e participação de homens e de mulheres em todas as esferas da vida pública, incluindo os media.

Deve notar-se que, dados os limites acima expostos, o regulador dos media não trabalha especificamente as questões de género per se. De acordo com as queixas que recebe sobre esta matéria, a ERC tem entendido por adequado identificar as possíveis situações em que se verifica uma discriminação e que sejam da responsabilidade de entidades que prossigam atividades de comunicação social, tendo em vista a condenação de tais condutas e a sensibilização para a prevenção de novas ocorrências.

Por outro lado, formalizou, em 2014, o desenvolvimento de uma linha de trabalho com vista à promoção do combate aos estereótipos de género e à igualdade de papéis entre homens e mulheres nos meios de comunicação social através da definição de um plano de ação assente em vários eixos. Através desta iniciativa, procura dar-se visibilidade àquelas dimensões, sempre que pertinente, nas deliberações, na monitorização sistemática de conteúdos televisivos e no desenvolvimento de análises específicas (a título de exemplo, a cobertura noticiosa dos crimes de violência doméstica nos telejornais em horário nobre dos canais de sinal aberto). Nas redes internacionais de reguladores de que faz parte, a ERC integra grupos de trabalho sobre esta temática, que se articulam na realização de estudos comparativos e no estabelecimento de diretrizes e recomendações (ERC, 2014).

Com efeito, as agências reguladoras contemporâneas aplicam métodos híbridos, que incluem a abordagem de «comando e controlo», mais consentânea com a imagem tradicional de autoridade de supervisão e fiscalização, mas também mecanismos de regulação informal (por exemplo, a promoção de iniciativas de corregulação e autorregulação) e intervenções regulatórias light que visam influenciar os regulados e os públicos (como a elaboração de diretivas ou a organização de ações de literacia mediática) (Lunt e Livingstone 2012, 36).

Deverá ter-se em conta que, na apreciação de situações que envolvem conteúdos mediáticos, é frequente a necessidade de proceder a uma ponderação quando existe conflito de direitos, por exemplo, entre a liberdade de expressão e o princípio da igualdade, para que ambos os direitos se conciliem dentro do possível sem que um deles leve ao completo sacrifício do outro. Nas palavras do constitucionalista Vieira de Andrade $(2009,301)$, existe uma «colisão ou conflito sempre que se deva entender que a Constituição protege simultaneamente dois valores ou bens em contradição, numa determinada situação concreta (real ou hipotética)». A solução para conflitos entre direitos «não pode, porém, ser resolvida sistematicamente através de uma preferência abstrata, com o mero recurso à ideia de uma ordem hierárquica dos valores constitucionais» (Vieira de Andrade 2009, 302). A solução passará, antes, por uma harmonização ou concordância prática, executada através de um critério de proporcionalidade na distribuição dos custos do conflito. 


\section{A atuação do regulador dos media quando o tema é a discriminação de género}

A intersecionalidade ancorada na teoria feminista propõe uma perspetiva não essencialista das categorias de classe, raça e etnicidade. Ao invés, os/as seus/ suas representantes (e.g. Collins 1993; Crenshaw 1994; Moraga e Anzaldúa 2015) defendem que tais categorias não são autónomas, mas deverão ser articuladas em simultâneo, numa compreensão mais profunda da discriminação de género enquanto distribuição desigual do poder e materialização de relações de privilégio/ opressão.

A intersecionalidade pretende, assim, analisar como interagem diferentes formas de desvantagens e opressão que afetam os indivíduos, procurando explicar-se, por esta via, a experiência específica de determinados grupos com base na classe, raça e etnicidade, entre outras categorias identitárias.

Por outro lado, é necessário compreender os media não apenas enquanto reflexo da realidade, mas no seu papel de construtores sociais da realidade (Couldry 2000, citado em Georgiou 2012), perspetiva sempre presente nas análises elaboradas pelo regulador.

De mencionar que a atuação regulatória na área dos conteúdos abarca uma variedade de meios (como a imprensa, rádio, televisão), géneros (e.g., entretenimento, informação, publicidade ${ }^{11}$ ) e conceitos (liberdade de imprensa, pluralismo e diversidade, exigência e rigor jornalísticos, entre outros), o que corresponde ao âmbito de intervenção, objetivos, atribuições e competências da ERC, tal como acima descritos.

Os conteúdos mediáticos são normalmente apreciados através de dois procedimentos principais:

i) Apreciação de queixas e participações de cidadãos e organizações da sociedade civil que visam conteúdos mediáticos específicos. As averiguações desta natureza podem também ser iniciadas por decisão do Conselho Regulador, o órgão máximo da ERC. O enquadramento das análises de casos é, regra geral, orientado pelos próprios termos usados nas queixas/ participações. Os trâmites procedimentais incluem o direito de os meios de comunicação exercerem o contraditório em relação ao objeto das queixas/ participações, sendo os argumentos incorporados na apreciação. Na conclusão, após a ponderação de todos os elementos, o Conselho Regulador delibera sobre a procedência da queixa/participação;

11 No que se refere especificamente aos conteúdos publicitários, a atuação da ERC consiste em fazer respeitar os princípios e limites legais sobre os mesmos em matérias cuja competência não se encontre legalmente conferida a outras instituições, como a Direção-Geral do Consumidor (Estatutos da ERC, artigo 24. ${ }^{\circ}$, n. ${ }^{\circ}$ 3, alínea b). Por conseguinte, a intervenção da ERC sobre a publicidade é limitada por esta repartição de atribuições com outros organismos. 
ii) Análise sistemática anual da programação (rádio e televisão) e da informação e do pluralismo político (dos noticiários em horário nobre dos canais generalistas de sinal aberto).

Na sequência de uma análise de caso, o Conselho Regulador delibera no sentido de arquivamento ou considera haver matéria para uma admoestação ou condenação.

No caso da monitorização de conteúdos, esta abordagem permite à ERC fazer um ponto de situação sobre as várias dimensões sob observação, definidas a partir de normativos legais que os órgãos de comunicação social devem respeitar. Esta visão macro permite ao Conselho Regulador identificar padrões e práticas mediáticas que, eventualmente, poderão justificar uma análise mais aprofundada ou a produção de recomendações. Esta informação é partilhada com os próprios órgãos de comunicação social e a sociedade.

\section{Análise sistemática dos conteúdos informativos}

A monitorização dos serviços noticiosos em horário nobre dos canais generalistas de sinal aberto (nomeadamente RTP1, RTP2, SIC e TVI) tem como quadro conceptual a diversidade, pluralismo, rigor e isenção, cuja verificação "pressupõe a interligação entre vários indicadores, como a sua análise ao longo do tempo» (ERC 2016, 70).

A operacionalização da diversidade e do pluralismo envolve a construção e análise de indicadores como a temática dominante das peças, os protagonistas e as fontes de informação, com o objetivo de «apreciar a existência de uma pluralidade cultural, política, social, económica e geográfica» (ERC 2016, 71).

Pretende-se perceber como e se as notícias televisivas espelham a diversidade nas suas várias aceções, e não tanto obter uma análise mais complexa, em múltiplos eixos identitários. Por conseguinte, é possível determinar os principais temas e fontes de informação que constituem o alinhamento dos noticiários e elencar as características dos protagonistas das peças informativas nacionais e internacionais, incluindo a nacionalidade e o sexo.

No que diz respeito à última categoria, o mais recente Relatório de Regulação (ERC 2016) indica que a maioria dos protagonistas dos blocos informativos televisivos é do sexo masculino (média de 72,9\%) (Figura 1).

Esta preponderância de homens associa-se às principais temáticas identificadas nos alinhamentos dos telejornais, em particular a política nacional e o desporto (em particular o futebol masculino), cujos conteúdos são sobretudo representados por homens (e.g., na política, presidente da República, primeiro-ministro e líderes partidários). As mulheres são sobretudo chamadas a protagonizar os conteúdos que reportam à ordem interna (e.g., testemunhas de acidentes e catástrofes), cultura (e.g., artistas), sociedade (e.g., familiares) e economia, finanças e negócios (e.g., trabalhadoras, desempregadas) (Tabela 1). 


\section{Figura 1}

Principal ator nos blocos informativos em horário nobre nos canais de sinal aberto em 2015, por sexo

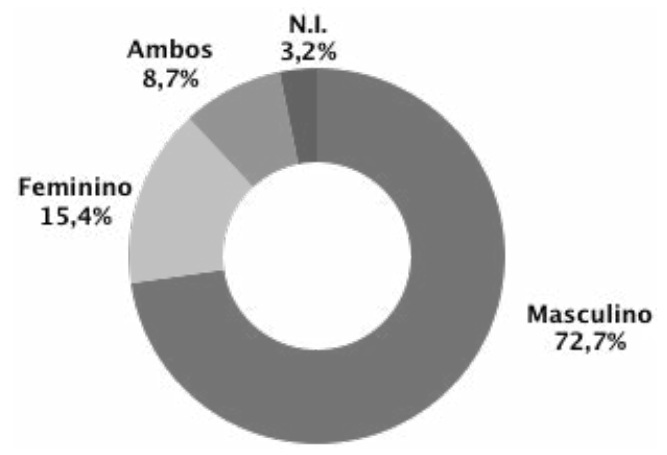

Nota: Total de peças analisadas em 2015 (Telejornal - RTP1; Jornal 2 - RTP2; Jornal da Noite - SIC; Jornal das $8-\mathrm{TVI})=2750$; Total de peças com ator principal $=2450$.

Fonte: ERC (2016)

\section{Tabela 1}

Principais temas por ator nos blocos informativos em horário nobre nos canais de sinal aberto em 2015*

\begin{tabular}{lccccc}
\hline \multicolumn{1}{c}{ Tema } & $\begin{array}{c}\text { Masculino } \\
\%\end{array}$ & $\begin{array}{c}\text { Feminino } \\
\%\end{array}$ & $\begin{array}{c}\text { Ambos } \\
\%\end{array}$ & $\begin{array}{c}\text { Não identificável } \\
\%\end{array}$ & $\begin{array}{c}\text { Total } \\
\%\end{array}$ \\
\hline Política nacional & 28,0 & 21,6 & 13,3 & 5,1 & 25,0 \\
Ordem interna & 10,2 & 15,6 & 21,0 & 47,4 & 13,2 \\
Desporto & 14,0 & 2,2 & 0,5 & 1,3 & 10,6 \\
Economia, finanças & 6,5 & 8,6 & 9,5 & 7,7 & 7,1 \\
e negócios & & & & & \\
Política & 8,1 & 3,0 & 4,3 & 6,4 & 6,9 \\
internacional & 5,8 & 10,2 & 6,7 & 1,3 & 6,4 \\
Cultura & 7,7 & 3,2 & 1,9 & 2,6 & 6,3 \\
Política europeia & 4,7 & 3,0 & 6,2 & 6,4 & 4,6 \\
Sistema judicial & 2,5 & 8,1 & 8,1 & - & 3,7 \\
Vida social & 2,6 & 3,0 & 5,2 & 7,7 & 3,0 \\
População & 1,4 & 8,6 & 5,2 & 1,3 & 2,9 \\
Sociedade & 1,8 & 2,7 & 5,2 & 5,1 & 2,3 \\
Relações laborais & 1,8 & 3,5 & 4,3 & 2,6 & 2,3 \\
Saúde e ação social & 1,5 & 1,6 & 2,4 & 3,8 & 1,7 \\
Comunicação & & & & {$[$ continua na página seguinte] }
\end{tabular}




\begin{tabular}{lccccc}
\hline Ciência e tecnologia & 0,7 & 2,7 & 1,0 & - & 1,0 \\
Urbanismo & 1,0 & 0,5 & 0,5 & - & 0,8 \\
Crença e religião & 1,0 & 0,5 & 0,5 & - & 0,8 \\
Educação & 0,4 & 0,3 & 2,9 & - & 0,6 \\
Ambiente & 0,3 & 1,1 & 1,4 & 1,3 & 0,6 \\
Defesa & 0,1 & - & - & - & 0,1 \\
\hline \multirow{2}{*}{ Total } & $\mathbf{1 0 0 \%}$ & $\mathbf{1 0 0 \%}$ & $\mathbf{1 0 0 \%}$ & $\mathbf{1 0 0 \%}$ & $\mathbf{1 0 0 \%}$ \\
& $\mathbf{( 1 7 5 1 )}$ & $\mathbf{( 3 7 1 )}$ & $\mathbf{( 2 1 0 )}$ & $\mathbf{( 7 8 )}$ & $\mathbf{( 2 4 1 0 )}$ \\
\hline
\end{tabular}

* Devido aos arredondamentos, os totais podem não corresponder à soma das parcelas.

Nota: Total de peças analisadas em 2015 (Telejornal - RTP; Jornal 2 - RTP2; Jornal da Noite - SIC; Jornal das $8-\mathrm{TVI})=2750$; Total de peças com ator principal $=2450$.

Fonte: ERC (2016)

Consegue perceber-se que a representação de homens e de mulheres nas notícias tende a seguir uma certa estereotipização de papéis sociais, em linha com padrões de cobertura identificados a nível nacional (Silveirinha 2008; Cerqueira e Cabecinhas 2012; Martins 2015) e internacional (Macharia et al 2015). A ERC continua a monitorizar e a acompanhar anualmente a evolução destes indicadores, que indiciam a persistência de um desequilíbrio da visibilidade de homens e de mulheres nos principais serviços informativos nacionais. Como já se mencionou, esta tendência é reforçada pela preponderância noticiosa de temas da área da política nacional e do futebol masculino, maioritariamente protagonizados por homens.

Estes indicadores são partilhados com a Comissão de Igualdade de Género (CIG) e com as autoridades reguladoras de outros países, tendo como premissa que a sensibilização para a igualdade de género nos media é mais eficaz quando suportada numa atuação interinstitucional, em rede.

\section{Análises casuísticas de conteúdos mediáticos}

Como já se referiu, os próprios termos em que os cidadãos se expressam nas queixas/ participações sobre conteúdos mediáticos orientam a apreciação do respetivo objeto. Por conseguinte, as problemáticas tendem a ser perspetivadas de modo essencialista e autónomo, ainda que haja exceções.

Entre 2007 e 2015, a ERC decidiu sobre 27 queixas/participações, submetidas tanto por cidadãos como por organizações da sociedade civil, ${ }^{12}$ em que se denunciava um alegado tratamento discriminatório baseado no género, em particular na

12 Segundo um levantamento efetuado pelas autoras que teve como base o universo de deliberações aprovadas pelo Conselho Regulador da ERC entre 2007 e 2015. As deliberações são públicas e estão disponíveis no site da ERC (www.erc.pt). 
imprensa e na televisão, e abrangendo diferentes géneros mediáticos, da informação ao entretenimento.

Foi reduzido o número de processos em que esteve em causa uma dupla discriminação, assente numa inter-relação entre género e nacionalidade, e que identificamos nos parágrafos seguintes. Estes casos interpelaram a ERC e desafiaram a tradicional abordagem regulatória essencialista baseada num único atributo. Descreve-se como foram estruturadas a análise e a apreciação em cada um deles e a que conclusões se chegou.

Um desses processos foi desencadeado por uma participação da Comissão para a Cidadania e Igualdade de Género (CIG) contra a edição de 11 de agosto de 2010 da Focus (revista semanal que deixou de se publicar em Portugal em 2012), devido à publicação de um artigo com destaque na capa sobre as mulheres de nacionalidade brasileira em Portugal, intitulado "Os segredos da mulher brasileira». Este título era precedido pelo antetítulo «Eles [homens portugueses] adoram-na, elas [mulheres portuguesas] odeiam-na». O destaque foi acompanhado pela imagem de um corpo de uma mulher jovem, de cabelos longos e morena, de costas, com grande plano das nádegas, vestindo um biquíni de tons amarelo e verde, as cores da bandeira do Brasil.

\section{Figura 2}

Capa da revista Focus, edição de 11 de Agosto de 2010

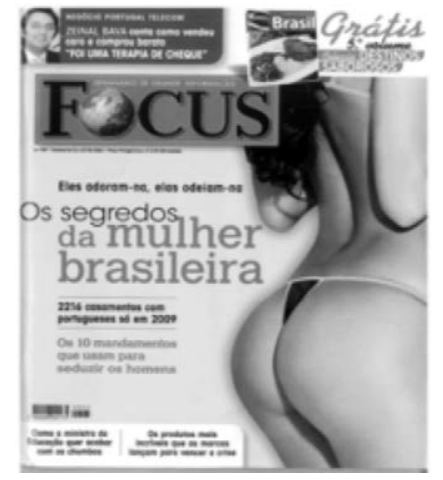

A CIG argumentou que esse tratamento configurou uma representação sexualizada e estereotipada e entendia ser «indispensável sensibilizar os meios de comunicação e todos os agentes envolvidos para a importância de boas práticas de promoção da cidadania inclusiva, bem como para o papel fundamental que podem desempenhar na desconstrução de estereótipos de género» (ERC, 2011a, 1).

A ERC apreciou a participação à luz dos princípios constitucionais da dignidade humana e da igualdade, destacando o importante papel que os media desempenham na desconstrução de estereótipos, enquanto «construções colectivas que 
tendem a definir, com recurso a factores desprimorosos, determinado grupo de indivíduos» (ERC, 2011a, 4). Na deliberação, enfatizou-se que a

promoção de uma verdadeira igualdade de género, que se materialize na igualdade de oportunidades, acesso ao emprego, carreiras e integração social, entre outros, implica a destruição de estereótipos pré-concebidos, oriundos de épocas passadas, todavia presentes na sociedade moderna, que tendem a desqualificar a mulher impondo-lhe barreiras artificiais à sua livre concretização e afirmação em sociedade (ERC 2011a, 4).

Da análise do caso, concluiu-se que a representação da mulher brasileira na capa desta edição da Focus «apresenta uma imagem essencialmente sexualizada, de pendor 'sensacionalista', contribuindo para o reforço da associação da mulher brasileira a uma representação de índole sexual» (ERC 2011a, 5). Este conjunto concorreu para perpetuar o lugar-comum de que as brasileiras constituem «uma ameaça» para as mulheres portuguesas. Adicionalmente, a mulher brasileira é discriminada por se associar a população brasileira à mera exibição do corpo.

Esta argumentação sustentou a decisão do Conselho Regulador de considerar a participação procedente, por transmissão de «uma ideia redutora da mulher brasileira, confinando-a a um estereótipo sexual, também discriminatório» (ERC 2011a, 6) e em contraste com a responsabilidade ética e social que a revista deveria assumir enquanto meio de comunicação.

A representação mediática das mulheres brasileiras esteve também no centro de participações enviadas à ERC pela Associação ComuniDária, o Grupo de Articulação do Manifesto e particulares contra o programa de humor "Café Central», da RTP2, exibido em 2011. Os participantes referiram-se a uma das personagens, Gina, apresentada, a seu ver, como mulher «estereotipada, hipersexualizada, desvalorizada e estigmatizada» (ERC 2011b, 1) e denotando preconceito em relação às mulheres brasileiras em Portugal. Um dos participantes entendeu que esta representação, como «prostituta e maníaca sexual», poderia ser interpretada como «machismo e sexismo» e «racismo, pois inferioriza, essencializa e estigmatiza essas mulheres por supostas características fenotípicas, comportamentais e culturais comuns» (ERC 2011b, 2). Denunciou-se, assim, a alegada ofensa à igualdade de género e à dignidade humana, por atitude discriminatória, racista e xenófoba.

Exercendo o contraditório, a RTP sublinhou que o programa em causa era de índole humorística, destinado a um «público adulto e esclarecido». Não apenas Gina, mas todos os personagens evocavam estereótipos compostos por «imagens simbólicas que mais facilmente se associam aos tipos que representam, designadamente, o taxista de «baixo nível», benfiquista ferrenho, o simpatizante do Bloco de Esquerda, intelectual e vegetariano». Gina nem sequer seria brasileira mas uma portuguesa do Montijo (ERC 2011b, 3).

Na análise foi salientado que a liberdade de expressão não poderá ofender a dignidade da pessoa humana, tanto mais ostensiva quanto maior a vulnerabilidade do grupo-alvo. Porém, nos programas humorísticos, pelo seu caráter mais 
transgressivo - portanto, desafiando os limites da liberdade de expressão e de criação -, são mais alargados os horizontes de aplicação das normas que devem orientar a transmissão de conteúdos, neste caso, televisivos. Os programas de humor, dependendo das respetivas características, requerem «um trabalho de descodificação e de desconstrução, nem sempre ao alcance dos públicos, atendendo ora à sua sensibilidade [...] ora ao seu grau de maturidade, que poderá não permitir a compreensão de significados da ordem do simbólico» (ERC 2001b, 11).

Na situação concreta, o Conselho Regulador concluiu que seria percetível a intencionalidade humorística, a configuração do programa em «personagens-tipo» e que a composição da personagem Gina não consubstanciou, em suma, uma atitude discriminatória ou ofensiva para a comunidade em causa e atentatória dos direitos das mulheres (ERC 2011b, 13). Na verdade, a tipologia de conteúdos constitui uma variável relevante na apreciação de processos em que está em questão uma alegada dupla discriminação, baseada no sexo e na nacionalidade.

Num terceiro caso analisado pela ERC, em 2012, sobre alegado tratamento discriminatório das mulheres brasileiras pelos media, a participante é uma mulher de nacionalidade brasileira. Esta manifestou a sua indignação pela forma como um painel de convidados do talk show «Você na TV!» debateu o tema «De que falam os homens quando as mulheres não estão?» (ERC 2012a).

\section{Figura 3}

Talk show «Você na TV!», TVI, edição de 12 de maio de 2012

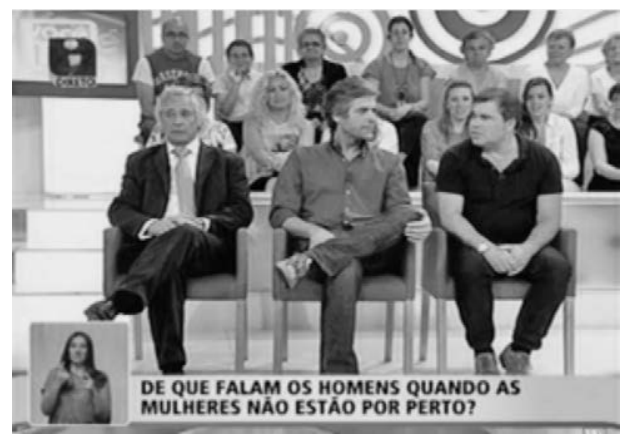

A crítica incidiu, especialmente, sobre comentários de um dos convidados.

GdaCP: Eu não percebo nada de automóveis (...). Para mim o automóvel é um objeto de luxo. [...] E para mim um objeto de luxo é uma brasileira. Portanto, um automóvel para mim é um meio de transporte. $\mathrm{O}$ artigo de luxo é uma brasileira. Portanto, mas falo. Com os meus amigos falo muito de brasileiras.

CF [apresentadora]: E falas em que aspeto? Porque elas são realmente gostosas? Sabem como lidar com um homem? Sabem como... 
GdaCP: São muito alegres! Fazem varão, sei lá! Fazem essas coisas! São umas artistas (ERC 2012a, 3).

Esta conversa foi acompanhada de risos dos intervenientes e da plateia que assistia em estúdio ao programa.

Mais tarde na emissão, a apresentadora deu conta de que várias mulheres brasileiras expressaram o seu desagrado por estes comentários na página online do programa e procurou enquadrar a conversa como uma «rábula».

No caso concreto, a ERC apreciou se a TVI incitou à discriminação em função do sexo e da nacionalidade de forma tão grave que justificasse a restrição da sua liberdade de programação. Reconheceu-se, nessa apreciação, que as declarações foram insultuosas e ofensivas para as mulheres brasileiras, pela comparação que as objetificou e promoveu uma representação estereotipada e sexualizada das mesmas, associando-as à prostituição. Porém, também foi tido em conta que o convidado verbalizou uma opinião pessoal, num espaço de opinião e comentário, no âmbito de um programa de entretenimento, cabendo-lhe, por isso, em primeira linha, a responsabilidade pelas mesmas. Destacou-se ainda a reação de reprovação dos apresentadores, concluindo-se que a TVI procurou minimizar os efeitos dos reparos discriminatórios (ERC 2012a, 7). Pelo que o Conselho Regulador decidiu não dar seguimento à participação, ainda que tenha alertado o operador televisivo para não permitir comentários discriminatórios em antena, que ferem as suscetibilidades das pessoas visadas, dado o seu conteúdo discriminatório, constitucionalmente proibido (ERC 2012a, 8).

Figura 4

Primeira página do Jornal de Notícias, edição de 26 de março de 2012

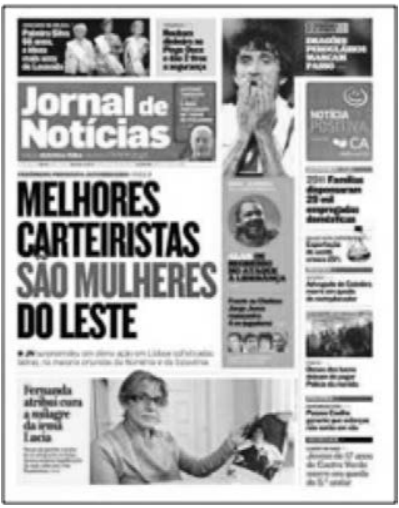

A representação de mulheres de «Leste» constituiu o objeto de participações submetidas à ERC pela associação SOS Racismo e o Alto Comissariado para a Imigração e Diálogo Intercultural (ACIDI), contra a manchete da edição de 26 de Março de 2012 do Jornal de Notícias, intitulada «Melhores carteiristas são mulheres do Leste» (ERC 2012b). 
A peça jornalística versou a elevada ocorrência de furtos nas zonas turísticas de Lisboa, em que se deu relevância à nacionalidade das alegadas autoras. Segundo a SOS Racismo, conotou-se as «mulheres de Leste» como as mais hábeis na prática do crime, atribuíram-se características criminosas inatas a uma comunidade específica. No entender da associação, tal não constituiu um facto, «mas sim uma opinião, não fundamentada, de carácter xenófobo, ofensivo para milhares de mulheres que residem em Portugal provenientes do Leste Europeu» (ERC 2012b, 1).

O ACIDI questionou igualmente a relevância do destaque conferido à nacionalidade como eixo estruturante da notícia e a veracidade da informação veiculada. A seu ver, o título configurou uma «apreciação qualitativa», que "pressupõe um estudo comparativo com «alegadas e alegados carteiristas» de outras nacionalidades, estudo esse que, quanto sabemos, não foi realizado» (ERC 2012b, 2).

Na sua apreciação, a ERC entendeu que a caracterização a partir da origem nacional constituiu um elemento estruturante no quadro informativo traçado no artigo alvo de críticas. No entanto, não encontrou fundamento para o título «Melhores carteiristas são mulheres do Leste», por ausência, no conjunto do trabalho jornalístico, do termo de comparação para qualificar as mulheres do Leste europeu de «melhores carteiristas», o que motivou a decisão de condenar a conduta do jornal. O Conselho Regulador concluiu que «a manchete, longe de ser meramente factual e informativa, revela contornos sensacionalistas, contrários às normas que norteiam a atividade jornalística e que poderão toldar a imagem das comunidades envolvidas» (ERC 2012b, 8).

\section{Conclusão}

Refletindo sobre a atuação da ERC na salvaguarda da igualdade e do tratamento não discriminatório em função do sexo na difusão de conteúdos pelas entidades que prosseguem atividades de comunicação social, sublinhou-se que o regulador dos media não é especialista ou trata especificamente as questões de género.

A intervenção da ERC no combate à discriminação de género está vinculada, em primeira instância, à proteção de direitos, liberdades e garantias constitucionalmente protegidos. Além disso, a proibição e a condenação de práticas que discriminam em função da ascendência, sexo, raça, língua, território de origem, religião, convicções políticas ou ideológicas, instrução, situação económica, condição social ou orientação sexual, quando da responsabilidade dos órgãos de comunicação social, encontram-se devidamente salvaguardadas na legislação setorial.

No quadro teórico da intersecionalidade, constatou-se que a apreciação dos conteúdos mediáticos pelo regulador, nas suas diferentes abordagens, tende a ser orientada por problemáticas vistas isoladamente e não entrecruzadas, o que, neste último quadro, permitiria uma compreensão mais articulada de múltiplas discriminações e opressões que afetam as diversas minorias sociais. No entanto, tanto 
nas análises sistemáticas como nas de casos, vislumbram-se abordagens em que se entrecruzam categorias ou estão em causa múltiplas discriminações, designadamente, género e nacionalidade.

A monitorização dos conteúdos informativos transmitidos em horário nobre - com recurso a grelhas de análise fundamentadas na densificação dos conceitos contidos nos normativos que regulam o setor da comunicação social, quanto à diversidade e ao pluralismo - permite identificar tendências que refletem a leitura mediática do real.

No caso do sexo dos atores destacados pelos conteúdos informativos, a ERC tem vindo a chamar a atenção, nos seus relatórios, para a prevalência dos protagonistas masculinos associados às temáticas que dominam os alinhamentos dos telejornais em horário nobre. Sendo a política nacional o tema dominante dos alinhamentos informativos, a opção por protagonistas dos partidos e da vida política enquanto atores destacados reflete a estrutura das instituições do campo político. O mesmo ocorre quando falamos das peças de desporto, onde o futebol masculino representa a quase totalidade dos conteúdos transmitidos. Cabe questionar as opções editoriais no que toca à seleção dos conteúdos emitidos nos noticiários em horário nobre dos canais de sinal aberto com claros reflexos sobre a ausência de diversidade dos temas e, consequentemente, nas áreas citadas, dos atores selecionados para a sua representação.

Estas decisões temáticas ao nível editorial são fruto de escolhas organizacionais cada vez mais condicionadas por uma orientação para o mercado das empresas de media (cf. Garcia 2009).

Na análise de queixas/participações em que estava em causa uma dupla discriminação, assente numa inter-relação entre género e nacionalidade, a apreciação da ERC foi desafiada a estruturar a sua análise em moldes distintos da tradicional abordagem essencialista baseada num único atributo. No entanto, o número reduzido de processos com aquelas características não permitiu ainda ao regulador dos media consolidar uma grelha de apreciação destes casos. Por outras palavras, a experiência regulatória nestas situações revela um caráter casuístico.

Algumas decisões do Conselho Regulador tornaram-se doutrinárias, no sentido em que estabelecem um juízo sobre situações com contornos semelhantes. Releva-se uma sensibilidade para formas de tratamento mediático que não correspondem ao princípio da igualdade e podem ser interpretadas como discriminatórias e legitimadoras da reprodução social de estereótipos que, como construções simbólicas coletivas e de caráter generalista, penalizam grupos específicos na sua totalidade.

No entanto, não se ignora que, ainda que devam ser definidas balizas de intervenção regulatória, em última instância cada caso exige uma análise, argumentação e apreciação per se.

Por exemplo, o enquadramento específico (tipo de conteúdo, género de programa) influencia de modo relevante a conclusão. Como se viu, face a conteúdos humorísticos ou espaços de comentário e opinião, o regulador tende a privilegiar 
a liberdade de expressão e de criação, não obstante reconhecer e alertar para certas manifestações que classifica como discriminatórias. Perante conteúdos jornalísticos em que se comprova uma violação dos princípios éticos, deontológicos e legais dos meios de comunicação informativos, a ERC relembra a responsabilidade ética e social dos media e aplica as respetivas sanções.

Reitera-se, por fim, que a apreciação de queixas e participações implica, frequentemente, a ponderação de valores entre a liberdade de expressão, de imprensa, de programação e a garantia do direito à igualdade e o tratamento não discriminatório.

A ERC, enquanto instância de heterorregulação, só em situações muito contadas e de gravidade indesmentível condena um órgão de comunicação social por violação dos limites à liberdade de imprensa (em sentido lato), e o fundamento dessa condenação deve ser claro, objetivo, no quadro da sua missão e atuação e das normas que lhe cumpre proteger.

\section{Referências bibliográficas}

Cerqueira, Carla, e Rosa Cabecinhas. 2012. «Políticas para a igualdade entre homens e mulheres nos media: da (inov)ação legislativa à mudança social». ex æquo 25: 105-118. Disponível no endereço http://www.scielo.mec.pt/pdf/aeq/n25/n25a09.pdf

Collins, Patricia Hill. 1993. «Toward a new vision: Race, class, and gender as categories of analysis and connection». Race, Sex and Class 1 (1): 25-45. URL estável: http://www. jstor.org/stable/41680038

Crenshaw, Kimberlee. 1994. «Mapping the margins: Intersectionality, Identity politics, and violence against women of color». In The Public Nature of Private Violence: The Discovery of Domestic Abuse, editado por Martha Fineman e Roxanne Mykitiuk, 93-118. Nova Iorque: Routledge.

ERC - Entidade Reguladora para a Comunicação Social. 2011a. «Deliberação 1/CONT-I/2011», de 5.1.2011. Disponível em http://www.erc.pt/documentos/newsletter/Deliberacao1CONTI2011.html

ERC. 2011b. «Deliberação 37/CONT-TV/2011», de 22.11.2011. Disponível no endereço http:// www.erc.pt/pt/deliberacoes/deliberacoes/2011?filter=Televis\%E3o

ERC. 2012a. «Deliberação 25/CONT-TV/2012», de 9.10.2012. Disponível no endereço http:// www.erc.pt/pt/deliberacoes/deliberacoes/2012?filter=Televis\%E3o

ERC 2012b. «Deliberação 14/CONT-I/2012», de 3.72012. Disponível no endereço http:// www.erc.pt/pt/deliberacoes/deliberacoes/2012?filter=Imprensa

ERC. 2014. «ERC Integra Plataforma de Reguladores para Promover Igualdade de Género», 23.6.214. Disponível no endereço http://www.erc.pt/pt/noticias/erc-integra-plataforma-de-reguladores-para-promover-igualdade-de-genero

ERC. 2016. Relatório de Regulação de 2015, Volume II. Lisboa: ERC.

Georgiou, Myria.2012. «Introduction: gender, migration and the media». Ethnic and racial studies, 35 (5): 791-799. Doi: https://doi.org/10.1080/01419870.2011.628041

Garcia, José Luís. 2009. «Introdução ao estudo dos jornalistas portugueses. Os jornalistas e as contradições do capitalismo jornalístico no limiar do século XXI». In Estudos sobre os jornalistas portugueses. Metamorfoses e encruzilhadas no limiar do século XXI, organizado por José Luís Garcia, 23-46. Lisboa: Imprensa de Ciências Sociais. 
Lunt, Peter, e Sonia Livingstone. 2012. Media Regulation. Governance and the Interests of Citizens and Consumers. Londres: Sage. Doi: https://doi.org/10.4135/9781446250884

Machado, Jónatas E. M., e Iolanda Rodrigues de Brito. 2013. Curso de Direito da Comunicação Social. Lisboa: Wolters Kluwer Portugal.

Macharia, Sarah et al. 2015. Global Media Monitoring Project 2015. Londres e Toronto: World Association for Christian Communication (WACC). Disponível no endereço http:// whomakesthenews.org/gmmp/gmmp-reports/gmmp-2015-reports

Martins, Carla. 2015. Mulheres, Liderança Política e Media. As lideranças de Maria de Lourdes Pintasilgo e de Manuela Ferreira Leite. Lisboa: Alêtheia.

Moraga, Cherrie, e Gloria Anzaldúa,. (2015). This Bridge Called My Back: Writings by Radical Women of Color. 4. ${ }^{\text {a }}$ ed. Albany: State University of New York Press.

Silveirinha, Maria João. 2008. «A Representação das Mulheres nos Media. Dos Estereótipos e 'Imagens de Mulher' ao 'Feminino' no Circuito da Cultura». In Comunicação e identidades sociais, organizado por João Pissarra Esteves, 103-108. Lisboa: Livros Horizonte.

Vieira de Andrade, José Carlos. 2009. Os Direitos Fundamentais na Constituição Portuguesa de 1976. 4. ${ }^{\text {a }}$ ed. Coimbra: Almedina.

Alexandra Figueiredo. Analista de media no Departamento de Análise de Media da ERC. Licenciada em Sociologia e pós-graduada em Comunicação, Cultura e Tecnologias de Informação, pelo ISCTE. Membro colaborador do SOCIUS/ISEG.

Carla Martins. Assessora do Conselho Regulador e coordenadora do Grupo de Trabalho para a Transparência da ERC. Licenciada e mestre em Filosofia, doutorada em Ciências da Comunicação, especialização em Media e Jornalismo. Professora da ULHT. Investigadora do CIEG. Autora de Política no Feminino (em coautoria, 2016. Alêtheia); Mulheres, Liderança Política e Media (2015, Alêtheia); e O Espaço Público em Hannah Arendt (2005, Minerva Coimbra).

Artigo recebido em 06 de fevereiro de 2017 e aceite para publicação em 01 de março de 2017. 